\title{
Treatment of Femoral Neck Fractures with Dynamic Hip Screw in Young Adults
}

\author{
Mustufa Pervez*1, Idrees Shah ${ }^{2}$, Muhammed Umer Ahmed ${ }^{3}$ and Fiza Hassan Shah ${ }^{3}$ \\ ${ }^{1}$ Department of Orthopedics, Ziauddin Hospital, Pakistan
}

${ }^{2}$ Department of Orthopedics, Ziauddin Hospital, Pakistan

${ }^{3}$ Ziauddin Hospital, Karachi, Pakistan

Received: March 09, 2018; Published: March 28, 2018

*Corresponding author: Mustufa Pervez, Department of Orthopedics, Ziauddin Hospital, Indus Residency, Block 4, Karachi, Pakistan, Email: mustufa_pervez@hotmail.com

\begin{abstract}
Dynamic hip screws have been a mainstay of treatment for intertrochanteric fractures of the proximal femur and are also used to treat femoral neck fractures. Femoral neck fractures are usually common in older age but can also present in younger individual usually due to high energy trauma. Treatment of these fractures in young adults is debated due to higher energy demands of the age and need to salvage the bone instead of opting for a hemi arthroplasty or total hip arthroplasty as with older patients. Different other treatment options such as multiple cannulated screws have also been proposed but there still lies no consensus for the ideal treatment of such fractures. Displaced fractures are commonly associated with a vascular necrosis of the femoral head and multiple researches have been performed in this regard but if success of union occurs after a Dynamic hip screw is performed, the patient is able to regain his near physiological hip. Good bone quality and no comorbids usually present as an advantage in younger patients but still the surgery haunts orthopedic surgeons with its non-union and a vascular necrosis rates. Good anatomical reduction and stable fixation remains a mainstay of the treatment and can be perpetuated by a further use of a de-rotation screw.
\end{abstract}

Keywords: Femoral Neck Fractures; Osteonecrosis

\section{Introduction}

Femoral neck fractures, though more prevalent in the elderly population, can occur in the young patients usually due to high energy trauma. Salvage of the femoral head is of prime concern to orthopedic surgeons given the age of the patients and there still lies a lack of consensus regarding the treatment of these kinds of fractures. Research and publications show a mixed result in this regard. These fractures are associated with a higher rate of osteonecrosis and nonunion and arthroplasty procedures are not ideal given the higher level of activity and age. Achieving an anatomic reduction and stable fixation is important and other factors such as timing of surgery and role of capsulotomy are still debatable. Dynamic hip screw (DHS) is based on the tension band principle which allows the screw to slide within the barrel to enable compression of the fracture at commencement of weight bearing. The union of the bone should ideally be primary type of bone healing which necessitates absolute stability at the fracture site. Other factors that make these kinds of fractures susceptible to nonunion are the intracapsular nature of the fracture and the synovial fluid also prevents blood clot formation. The intracapsular part also has no periosteal layer, hence the need for stable fixation with compression to achieve direct healing. Avascular necrosis presents as a common problem encountered after this method of fixation.

\section{Discussion}

\section{Types of Femoral Neck Fractures}

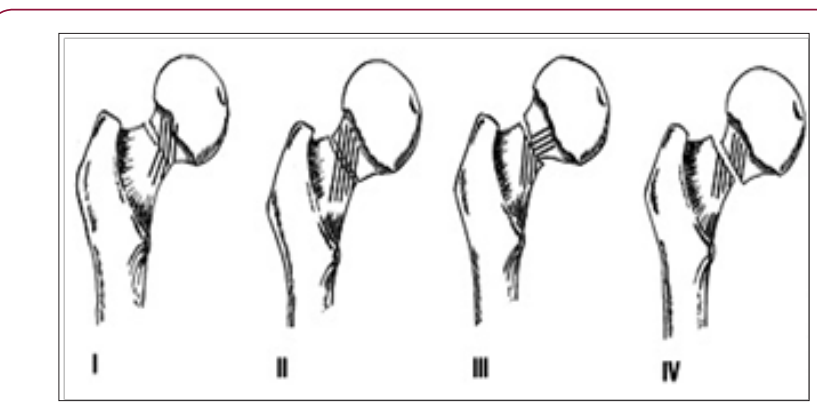

Figure 1: Gardens Classification of Hip Fractures I. Incomplete fracture II. Complete but undisplaced III. Complete fracture partially displaced IV. Complete fracture totally displaced. 
Different classification systems exist for the femoral neck fractures but the most commonly used are Gardens Classification and Pauwel's Classification. These systems attempt to differentiate the type of different fractures for the selection of an optimal treatment modality. The Garden's classification differentiates the femoral neck fractures into four types depending on the displacement and totality of the fracture. Type I and II fractures are UN displaced fractures but in type I fractures, the fracture line is incomplete. Type III and IV are complete fractures, Type III being partially displaced and Type IV being complete displaced (Figure 1).

\section{Dynamic Hip Screw}

Dynamic hip screw or sliding screw fixation consists of a lag screw, a side plate and cortical screws which fix the side plate to the proximal femoral shaft. The lag screw is inserted into the head of femur from the lateral aspect. For this surgery a C-arm image intensifier is required. The size of the hip is measured preoperatively on the X-ray to get an idea about the probable size. The patient is supine on the fracture table with feet padded and placed firmly in the table boots. Contra lateral leg is either dropped down or abducted and flexed in a thigh holder. After preparation of the patient, the proximal femur is exposed using a lateral incision extending from the greater trochanter to $8-10 \mathrm{~cm}$ distally. After bone exposure the guide wire is drilled into the proximal femur in ideally a centre-centre position and is measured. Triple reaming is done and the screw is inserted and a plate is applied to it which is secured with cortical screws (Figure 2). The idea behind the dynamic compression is that the femoral head component is allowed to move along one place and since bone responds to dynamic stress, the femur may undergo primary healing resulting in joint requiring no remodeling (Figure 3).

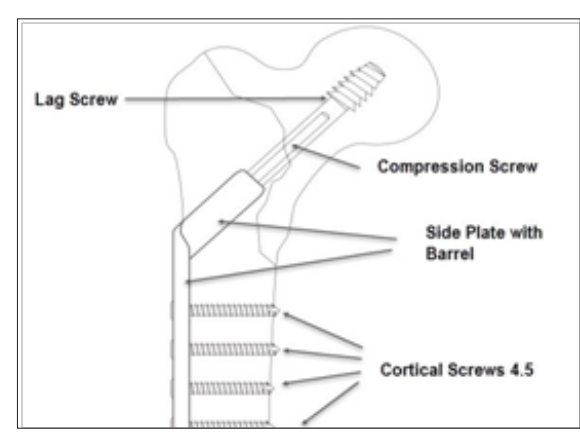

Figure 2: An illustration of Dynamic Hip Screw implant in the proximal femur.

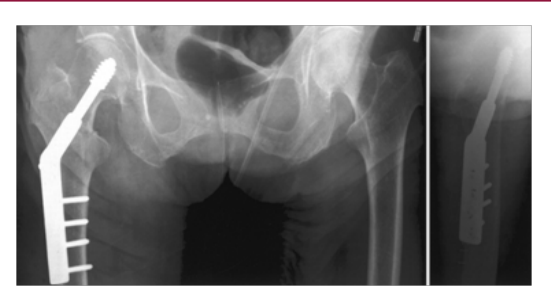

Figure 3: Xray Pelvis Anteroposterior and Lateral views showing a Dynamic Hip Screw Implant in the right proximal femur.
The treatment of femoral neck fractures has been debated for many years. The main issue during decision making is whether to fix it or to replace the neck. The optimal treatment for younger patients is still controversial and younger the patient, the more the orthopedic surgeon is obliged to pursue internal fixation [1]. Many factors can influence the decision namely the pre-injury functional status, mental ability and also the patient's demands. The criticism against internal fixation stems from its associated with higher association of non-union and osteonecrosis [2]. Nevertheless, when the femoral fractures heal, the patient has a chance of regaining their physiologically normal hip. Younger patients tend to have higher physiological reserves, good bone quality and usually no medical co-morbidities and the goal treatment is joint preservation. For internal fixation most orthopedic surgeons choose either a Dynamic Hip screw or multiple cannulated screws [3]. Tronzo in his research identified almost 100 different implants that are available for the fixation of this type of fracture [4].

Osteosynthesis with cannulated screws is a less invasive technique and reduces blood loss and soft tissue stripping but the Dynamic hip screw plate system provides a more stable fixation. Its disadvantages are large skin incisions, more soft tissue dissection, greater need for blood transfusion and a longer hospital stay. Makki showed no benefit in the union rates of osteonecrosis in fractures treated with either DHS alone or DHS with a de-rotational screw [5]. Furthermore Razik all studied 92 young patients and found that DHS supported with a de-rotational screw had siginificantly less osteonecrosis for Garden's type III and IV fractures [6]. Studies showed that age was an important factor while side or sex affected does not affect the final outcome and found no studies that show the role of these variables. According to Tolga Kaplan et all, physiological age rather than chronological age is more important in deciding the modality of treatment [7]. Most authors agree that the best position to fix the fracture is in anatomical reduction or slight valgus.

The results of osteosynthesis in young patients are debatable by presenting a considerable complication rates. However, little doubt is present that the most problematic complication is the occurrence of osteonecrosis [8]. Many variables have been associated with this complication after femoral neck fractures. Most literature does not support the differences in gender but higher rates of nonunion and AVN are more common in younger patients. Some explanations are given on the basis of high energy trauma and its correlation with dislocated fractures in young adults [9]. Lu-Yao et al published a meta-anyalysis of 106 published reports and concluded that the rate of loss of fixation or reduction after open reduction and internal fixation is about $16 \%$ (9-27\%) which is significantly higher than the risk of dislocation after hemiarthroplasties and total hip replacements [10]. The rate of osteonecrosis ranges from 12-86\%. Another controversial issue is the timing of the surgery. Barnes described a long term follow-up of 1503 sub capital fractures and concluded that the mortality rate increased if the operation was delayed more than 3 days following injury but no significant difference was found in osteonecrosis or late collapse when delaying the surgery upto 1 week [11]. 
Advocates of early surgery suggest that prompt reduction produces an unlinking of the proximal femoral vessels that leads to intracapsular decompression and restoration of the blood flow to the femoral head and minimizes the risk of osteonecrosis. Other studies also confirm that early surgery may decrease the rate of femoral head osteonecrosis while some studies show that there is no difference in osteonecrosis with more than 24 hour delay [12]. There also lays a controversy regarding the screw position in the femoral head. The main discussion concerns central versus posteriorinferior screw placement. There is a consensus that the anteriorsuperior position should be avoided because it is associated with a higher failure rate as called to attention by Barnes et al. There has been no paper in the literature regarding the position of the screw in relation to osteonecrosis of the femoral head. As the demands of young individuals are more as compared to an elderly patient and due to life spans of prosthesis, surgeons prefer to salvage the head in younger patients [13-20]. A recent research about treating young patients with DHS operated the fracture within 3 to 7 days. The union time was found to be 13.5 weeks and AVN was found only in 1 case for which implant removal and hemiarthroplasty was done and only 2 cases of non-union were found post operatively at an interval of 9 months. 1 patient developed superficial wound infection which responded to intravenous antibiotics and subsided [21-45].

\section{Conclusion}

The incidence of a vascular necrosis in patients younger than 55 with displaced femoral neck fractures that were treated with a Dynamic Hip Screw was found to be around 23.9\%. No significant association between time to surgery, type of fracture and the application of a de-rotation screw with a vascular necrosis or nonunion was found.

\section{References}

1. Carlos Roberto Schwartsmanna, Henrique Marquardt Lammerhirtb, Leandro de Freitas Spinelli b, Ary da Silva Ungaretti Netob (2017) Treatment of displaced femoral neck fractures in young patients with DHS and its association to osteonecrosis. Rev Bras Ortop 53(1): 82-87.

2. Shabnam Samsami, Sadegh Saberi, Sanambar Sadighi (2015) Comparison of Three Fixation Methods for Femoral Neck Fracture in Young Adults: Experimental and Numerical Investigations. J Med Biol Eng 35(5): 566-579.

3. Mandeep Singh, Deependra Sonkar, Rahul Verma, Jiten Shukla, Sanjiv Gaur (2017) Comparison of the functional outcome of DHS versus cannulated cancellous screws in pauwels type II and III fracture neck femur in young adults. International Journal of Orthopaedics Sciences 3(2): 745-749.

4. Ly TV, Swiontkowski MF (2014) Treatment of femoral neck fractures in young adults. Journal of Bone and Joint Surgery American 90: 22542266.

5. Haidukewych GJ, Rothwell WS, Jacofsky DJ, Torchia ME, Berry DJ (2014) Operative treatment of femoral neck fractures in patients between the ages of fifteen and fifty years. The Journal of Bone \& Joint Surgery 86: $1711-1716$

6. Liporace F, Gaines R, Collinge C, Haidukewych GJ (2017) Results of internal fixation of pauwels type-3 vertical femoral neck fractures. The Journal of Bone \& Joint Surgery 90: 1654-1659.
7. Sfeir C, Ho L, Doll BA, Azari K, Hollinger JO (2005) Fracture repair. In JR Lieberman \& GE Friedlaender (Eds.), Bone regeneration and repair: biology and clinical applications. Totowa, Humana Press, USA pp. 21-43.

8. Roerdink WH, Aalsma AMM, Nijenbanning G, van Walsum AD (2009) The dynamic locking blade plate, a new implant for intracapsular hip fractures: biomechanical comparison with the sliding hip screw and Twin Hook. Injury 40: 283-287.

9. Ghoodship AE, Kenwright J (1985) The influence of induced micromovement upon the healing of experimental tibial fractures. Journal of Bone and Joint Surgery British 67: 650-655.

10. Claes LE, Wilke HJ, Augat P, Rubenacker S, Margevicius, KJ (1995) Effect of dynamization of gap healing of diaphyseal fractures under external fixation. Clinical Biomechanics 10: 227-234.

11. Augat P, Merk J, Ignatius A, Margevicius K, Bauer G, et al. (1996) Early, full weight bearing with flexible fixation delays the healing of experimental fractures. Clinical Orthopaedics and Related Research 328: 194-202.

12. Rogmark C, Carlsson A, Johnell O, Sernbo I (2002) A prospective randomised trial of internal fixation versus arthroplasty for displaced fractures of the neck of the femur. Functional outcome for 450 patients at two years. J Bone Joint Surg Br 84: 183-188.

13. Tidermark J, Ponzer S, Svensson O, Söderqvist A, Törnkvist H (2003) Internal fixation compared with total hip replacement fordis placed femoral neck fractures in the elderly. A randomised, controlled trial. J Bone Joint Surg Br 85: 380-388.

14. Blomfeldt R, Törnkvist H, Ponzer S, Söderqvist A, Tidermark J (2005) Comparison of internal fixation with total hip replacementfor displaced femoral neck fractures. Randomized, controlled trial performed at four years. J Bone Joint Surg Am 87(8): 1680-1688.

15. Chammout GK, Mukka SS, Carlsson T, Neander GF, Stark AW, et al. (2012) Total hip replacement versus open reductionand internal fixation of displaced femoral neck fractures: arandomized long-term follow-up study. J Bone Joint Surg Am 94(21): 1921-1928.

16. Bhandari M, Devereaux PJ, Swiontkowski MF, Tornetta P, Obremskey W, et al. (2003) Internal fixation compared with arthroplasty for displaced fractures of the femoral neck. Ameta-analysis. J Bone Joint Surg Am 85(9): 1673-1681.

17. Lu Yao GL, Keller RB, Littenberg B, Wennberg JE (1994) Outcomes after displaced fractures of the femoral neck. A meta-analysis of one hundred and six published reports. J Bone Joint Surg Am 76(1): 15-25.

18. Haidukewych GJ, Rothwell WS, Jacofsky DJ, Torchia ME, Berry DJ (2004) Operative treatment of femoral neck fractures in patients between the ages of fifteen and fifty years. J Bone Joint Surg Am 86(8): 1711-1716.

19. Swiontkowski MF, Harrington RM, Keller TS, Van Patten PK (1987) Torsion and bending analysis of internal fixation techniques for femoral neck fractures: the role of implant design and bone density. J Orthop Res 5(3): 433-444.

20. Singh GK, Deshmukh RG (2006) Uncemented Austin-Moore and Cemented Thompson Unipolar Hemiarthroplasty for Displaced fracture Neck of Femur Comparison of Complications and Patient Satisfaction. Injury 37(2): 169-174.

21. Nather A, Seow CS, Lau P, Chan A (1995) Mortality and morbidity for elderly patients with fracture neck of femur treated by hemiarthroplasty injury. J Bone Joint Surg 26: 187-190.

22. Johansson T, Jacobsson SA, Ivarsson I (2000) Internal fixation versus total hip arthroplasty in treatment of displaced femoral neck fractures, a prospective randomized study of 100 hips. Acta Orthop Scand 71: 597602.

23. Rogmark C, Carlsson A, Johnell O, Sanbo I (2002) A prospective randomized trial of internal fixation versus arthroplasty for displaced fractures of neck of femur. Functional outcome for 450 patients at two years. J Bone Joint Surg Br 84: 183-188. 
24. Saudan M, Lubbeke A, Sadowski C (2002) Pertrochanteric fractures: is there an advantage to an intramedullary nail? a randomized, prospective study of 206 patients comparing the dynamic hip screw and proximal femoral nail. J Orthop Trauma 16: 386-393.

25. Utrilla AL, Reig JS, Munoz FM, Tufanisco CB (2015) Trochanteric gamma nail and compression hip screw for trochanteric fractures: a randomized, prospective, comparative study in 210 elderly patients with a new design of the gamma nail. J Orthop Trauma 19: 229-233.

26. Rogmark C, Carlsson A, Johnell O, Sanbo I (2002) Primary hemiarthroplasty in old patients with displaced femoral neck fracture: A 1 year follows up of 103 patients aged 80 years Acta orthopaedica Scandinavica 73(6): 605-610.

27. (1980) The classic, The unsolved fracture: Kellogg Speed Clin Orthop Relat Res 152: 3-9.

28. Bachiller FG, Caballer AP, Portal LF (2002) Avascular necrosis of the femoral head after femoral neck fracture. Clin Orthop Relat Res 399: 87109.

29. Zetterberg CH, Elmerson S, Andersson GB (1984) Epidemiology of hip fractures in Göteborg, Sweden, 1940-1983. ClinOrthopRelat Res 191: 43-52.

30. S Kumar, D Bagchi (2009) Fractures Of The Neck Of The Femur- Treated With Multiple Cannulated Screws In Younger Patients -A Study Of 40 Cases. The Internet Journal of Orthopedic Surgery 18(1).

31. Protzman RR, Burkhalter WE (1976) Femoral-neck fractures in young adults. J Bone Joint Surg Am. 58(5): 689-695.

32. Dedrick DK, Mackenzie JR, Burney RE (1986) Complications of femoral neck fracture in young adults. J Trauma 26(10): 932-937.

33. Swiontkowski MF, Winquist RA, Hansen ST (1984) Fractures of the femoral neck in patients between the ages of twelve and forty-nine years. J Bone Joint Surg Am 66(6): 837-846.

34. Jain R, Koo M, Kreder HJ, Schemitsch EH, Davey JR, et al. (2002) Comparison of early and delayed fixation of subcapital hip fractures in patients sixty years of age or less. J Bone Joint Surg Am 84(9): 16051612.

35. Liporace F, Gaines R, Collinge C, Haidukewych GJ (2008) Results of internal fixation of Pauwels type-3 vertical femoral neck fractures. J Bone Joint Surg Am 90(8): 1654-1659.

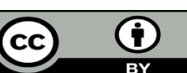

This work is licensed under Creative Commons Attribution 4.0 License

Submission Link: https://biomedres.us/submit-manuscript.php
36. Deneka DA, Simonian PT, Stankewich CJ, Eckert D, Chapman JR, et al (1977) Biomechanical comparison of internal fixation techniques for the treatment of unstable basicervical femoral neck fractures. J Orthop Trauma 11: 337-343.

37. R Whitman (1927) Orthopaedic Surgery, Kimpton, London (1927). Leadbetter. A treatment for fracture of the neck of the femur J Bone Joint Surg, pp. 931.

38. Hoekma HL, Van Den Ende CH, Ronday HK (2003) Comparison of the responsiveness of the Harris Hip Score with generic measures for hip function in osteoarthritis of the hip function in osteoarthritis of the hip: Ann Rheum Dis 62: 935-938.

39. RG Tranzo (1974) Symposium on fractures of the hip. Special considerations in management. Orthopedic Clinics of North America 5: 571-583.

40. Cummings SR, Nevitt MC (1994) Non-skeletal determinants of fractures: the potential importance of mechanics of falls. Osteoporosis Int pp. S6770 .

41. KBL Lee, TS Howe, HC Chang (2008) Cancellous YS Lee, SH Chen, YH Tsuang, HL, Huang TY Lo, CR Huang, Internal fixation of undisplaced femoral neckfractures in the elderly: a retrospective comparison of fixation methods. Journal of Trauma: Injury, Infection and Critical Care 64(1): 155-162.

42. MJ Parker, C Blundell (1998) Choice of implant for internal fixation of femoral neck fractures. Meta-analysis of 25 randomised trials including 4925 patients. Acta Orthopaedica Scandinavica 69(2): 138-143.

43. WC Chen, SW Yu, IC Tseng, JY Su, YK Tu, et al. (2005) Treatment of undisplaced femoral neck fractures in the, elderly. Journal of Trauma 58(5): 1035-1039.

44. RS Garden (1964) Stability and union in subcapital fractures of the femur. Journal of Bone and Joint Surgery B 46: 630-647.

45. J Keating (2010) Femoral neck fractures, in Rockwood and Green's, Fractures in Adults, RW Bucholz, JD Heckman, CM Court Brown, P Tornetta III (Eds.)., Lippincott Williams \& Wilkins, $7^{\text {th }}$ Edn.

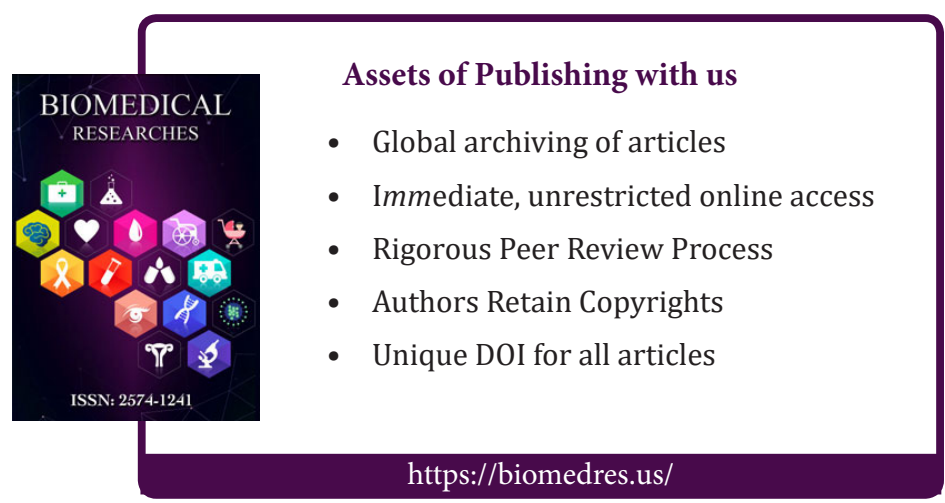

